\title{
Main Duct Pancreatic Intraductal Papillary-Mucinous Neoplasm
}

National Cancer Institute

\section{Source}

National Cancer Institute. Main Duct Pancreatic Intraductal Papillary-Mucinous

Neoplasm. NCI Thesaurus. Code C113664.

An intraductal papillary-mucinous neoplasm of the pancreas that arises from the main pancreatic duct. 